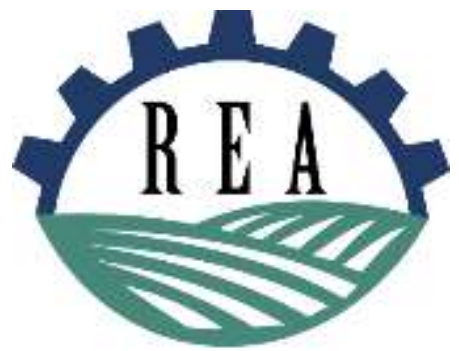

Revista de Economia e Agronegócio - REA

ISSN impresso: 1679-1614

ISSN online: $2526-5539$

Vol. 16 | N. 2 | 2018

EDITORIAL

\title{
Políticas públicas para agricultura: novas questões e velhos dilemas
}

\author{
Marcelo José Braga* \\ * Universidade Federal de Viçosa, Departamento de Economia Rural e Instituto de \\ Políticas Públicas e Desenvolvimento Sustentável, Viçosa, MG, Brasil. \\ E-mail: mjbraga@ufv.br
}

Do ponto de vista da ciência econômica, a ocorrência de falhas de mercado é a principal justificativa para a intervenção do Estado na economia. No caso da agricultura, a presença de elevados níveis de riscos e incertezas dificulta o processo de tomada de decisão. Com isso, Johnson (1947) desenvolveu a abordagem teórica que justificava, naquele período, o papel do governo de intervir nos mercados para garantir estabilidade de preços e renda aos produtores rurais.

Em 1961, Bruce F. Johnston e John W. Mellor publicaram um influente artigo em que definem o papel da agricultura no processo de desenvolvimento econômico de um país. Conforme esses autores, o setor deveria liberar mão de obra para a indústria, fornecer alimentos e matériasprimas para o setor urbano, gerar divisas estrangeiras para financiar o desenvolvimento, transferir poupanças para investimentos na indústria e formar mercados para bens industriais (Jonhston; Mellor, 1961). Essas justificativas serviram de base para a formulação de políticas agrícolas que empregassem os instrumentos de crédito, seguro e extensão rural, bem como para a pesquisa agropecuária pública, como no caso brasileiro.

Assim, o Estatuto da Terra (Lei n $\left.{ }^{\circ} 4.504 / 1964\right)$ estabeleceu a definição de política agrícola como "o conjunto de providências de amparo à propriedade da terra, que se destinem a orientar, no interesse da economia rural, as atividades agropecuárias, seja no sentido de garantir-lhes o pleno emprego, seja no de harmonizá-las com o processo de industrialização do país" (BRASIL, 2018). 
Ao longo do tempo, outros papéis foram atribuídos para a política agrícola, como preservação ambiental, redução da pobreza, mitigação dos efeitos da mudança climática, segurança alimentar, entre outros. Mueller (2010) define duas áreas de atuação para o setor público agrícola. A primeira, que o autor denomina técnica, é constituída pela normatização da produção, das atividades de ensino, pesquisa e extensão e da defesa agropecuária. Já a segunda, consiste na "área de formulação e condução de ações e políticas macrossetoriais para a agropecuária e de captação de recursos e de gestão de ações de estímulo e incentivo de interesse da agropecuária".

Em 1968, Gordon Smith realizou uma das primeiras avaliações da política agrícola brasileira, no período de 1950 a 1967. Àquela época, o autor constatou a inadequação e as distorções das políticas de crédito rural e de preços mínimos. Para o referido autor, havia um despreparo dos técnicos do Ministério da Agricultura em formular e implementar as políticas agrícolas conforme as recomendações já consolidadas na literatura existente (Smith, 1968).

Ao longo dos últimos 50 anos da publicação do referido trabalho, apesar de alguns resultados positivos, os problemas centrais parecem continuar os mesmos, a despeito do aparato do Estado na formulação, implementação e avaliação das políticas públicas e da melhor capacitação dos gestores públicos.

Para Mueller (2010), a ciência econômica analisa a política agrícola com a preocupação de construir alternativas que gerem a maximização do bemestar social. Entretanto, a análise econômica desconsidera a capacidade dos grupos de interesse de pressionarem por medidas que lhes tragam maiores benefícios, em detrimento dos impactos negativos que possam ter. Para o referido autor, a formulação de políticas agrícolas deve combinar estas duas dimensões, a racionalidade econômica e a ação dos grupos de interesse, que exercem pressões políticas, sociais, econômicas, ambientais e internacionais. Assim, o trabalho de Smith (1968) falhou ao empregar somente a abordagem da racionalidade na avaliação da política agrícola.

Já para Buainain et al. (2013), ao avaliar incorretamente as transformações do ambiente, o Estado brasileiro tem implementado ações equivocadas, que expressam uma "confusão de racionalidades: de um lado, refletindo a persistência de políticas herdadas do projeto de modernização na década de 1960, e de outro, introduzindo novas visões e instrumentos de regulação por meio de mercados". Também, Carvalho (1989) identificou a falta de consistência da política agrícola brasileira. Já Lopes (1986), introduziu o termo "risco institucional", que foi definido como o risco criado a partir das intervenções do governo nos mercados agropecuários, por meio de congelamentos de preços e alterações nos seus mecanismos de funcionamento. 
Santana et al. (2014) analisaram as políticas agrícolas brasileiras no período 1960-2014. Os autores identificaram quatro períodos distintos, assim denominados:

a) Intervenção planejada, entre as décadas de 60 e 80, que culminou na modernização da agricultura, a partir das mudanças estruturais na base técnica, econômica e social.

b) Intervenção conjuntural, na década de 80 , de caráter imediatista e caótico, com ações que tiveram o efeito de desestabilizar os mercados e criar uma nova modalidade de risco no setor, o risco institucional.

c) Intervenção baseada no mercado, ao longo dos anos 90, com o sistema de preços promovendo a alocação de recursos e remuneração dos produtores, após a estabilização da economia com o Plano Real.

d) Intervenção focada em grupos fragilizados e em situações de falhas de mercado, nos anos recentes, como nos casos da agricultura familiar e da mitigação e adaptação às mudanças climáticas, e na criação de um sistema de segurança, proteção e defesa agropecuária.

Ao longo dessas seis décadas, identifica-se que as políticas públicas para a agropecuária brasileira têm passado por significativas mudanças. Anteriormente, o emprego de instrumentos intervencionistas foi substituído por redução da participação dos gastos médios anuais com políticas agrícolas nos gastos totais do governo federal.

A partir dessa orientação da intervenção focada em grupos fragilizados e em situações de falhas de mercado, Chaddad et al. (2006) definem que as políticas agrícola e agrária deveriam ter como objetivo "a inserção competitiva e sustentável do produtor nas cadeias produtivas que compõem o sistema agroindustrial, no país e no exterior". Estas deveriam contemplar os seguintes pontos: expansão de oferta de bens públicos (infraestrutura, defesa sanitária, P\&D, extensão rural e informação sobre o mercado), ampliação dos instrumentos de gestão de riscos (seguro rural, contratos futuros e derivativos), fortalecimento da proteção jurídica aos direitos de propriedade, avaliação dos programas de subsídios diretos, aumento da agressividade nas negociações comerciais internacionais, desenvolvimento de programas de capacitação técnica e gerencial para produtores e desenvolvimento de um sistema nacional de certificação de qualidade e rastreabilidade de alimentos.

Na última década, observou-se um crescimento do número de políticas públicas para agricultura, traduzindo um aumento de esforço do governo. Entretanto, pouco se identificou em termos de resultados efetivos dessas políticas, conforme será discutido a seguir.

Para ilustrar o aumento desse esforço, registra-se os casos da agricultura familiar e da gestão de riscos agropecuários. 
Em 2013, o MDA registrava 20 "políticas públicas" para a agricultura familiar. Estas recebiam as seguintes denominações: PRONAF (Programa Nacional de Fortalecimento da Agricultura Familiar), PNATER (Política Nacional de Assistência Técnica e Extensão Rural), PAA (Programa de Aquisição de Alimentos), PNAE (Programa Nacional de Alimentação Escolar), PNCF (Programa Nacional de Crédito Fundiário), PAC 2 (Programa de Aceleração do Crescimento), SUASA (Sistema Unificado de Atenção à Sanidade Animal), Terra Legal, Programa Cadastro de Terra e Regularização Fundiária, Terra Forte, Biodiesel (Programa Nacional de Produção e Uso do Biodiesel), Garantia Safra, Reforma Agrária, PRONERA (Programa Nacional de Educação na Reforma Agrária), PRONATEC (Programa Nacional de Acesso ao Ensino Técnico e Emprego), PNDTR (Programa Nacional de Documentação da Trabalhadora Rural), Organização Produtiva das Mulheres Rurais, Territórios da Cidadania, Arca das Letras e PROINF (Programa de Apoio a Projetos de Infraestrutura e Serviços em Territórios Rurais).

No caso da gestão de riscos agropecuários, o Banco Mundial (2015) identificou 25 principais planos e programas federais abrangendo as várias dimensões da questão e atingindo amplo grupo de agricultores. Tais projetos envolviam desde os riscos de produção, como Zoneamento Agrícola de Risco Climático (ZARC), Subvenção ao Prêmio do Seguro Rural (PSR), Programa de Garantia da Atividade Agropecuária (PROAGRO) e Programa de Garantia da Atividade Agropecuária da Agricultura Familiar (PROAGRO MAIS), passando por riscos de mercado, como Prêmio Equalizador Pago ao Produtor (PEPRO), Aquisição do Governo Federal (AGF) e Contrato de Opção de Venda (COV), até os riscos do ambiente de negócios, que incluíam o Programa de Investimento em Logística (PIL), Programa para Construção e Ampliação de Armazéns (PCA) e Programa de Incentivo à Irrigação e à Armazenagem (MODERINFRA).

Verifica-se, nesses casos, o aumento do número de políticas isoladas e fragmentadas, a falta de sinergia e integração e até a competição entre elas. O caso a seguir apresentado, da Política Nacional de Assistência Técnica e Extensão Rural, é emblemático e representativo desses problemas.

A PNATER apresenta como objetivos o desenvolvimento do meio rural de forma sustentável, compatível com a utilização adequada de recursos naturais e preservação do meio ambiente; a adoção de agricultura de base ecológica; a implantação de ações para garantir a segurança alimentar e nutricional sustentável; a viabilização de estratégias para geração de novos postos de trabalhos agrícolas e não agrícolas, entre outros (MDA, 2017). Quanto à forma de atuação, a PNATER incorpora a visão de que a ATER brasileira deveria organizar-se como um "Sistema Nacional Descentralizado de ATER Pública", do qual deveriam participar, juntamente com as entidades governamentais, outras instituições, como ONGs, empresas privadas, sindicatos e cooperativas, caracterizando o novo sistema de ATER como uma "pluriatividade de formas institucionais" (PEIXOTO, 2009). 
A Tabela 1 apresenta dados do acesso à extensão rural, conforme os resultados dos Censos Agropecuários de 2006 e 2017. Inicialmente, observase que a parcela de estabelecimentos que acessam a política é pequena e decrescente ao longo do período. Mesmo diante da ampliação das ações de política de ATER nos anos recentes, somente $22 \%$ e $20 \%$ dos estabelecimentos a acessaram em 2006 e 2017, respectivamente.

Tabela 1. Participação de propriedades que receberam assistência técnica, participação no número de propriedades e VBP, por região, em 2006 e 2017

\begin{tabular}{lcccccc}
\hline & \multicolumn{2}{c}{$\begin{array}{c}\text { Assistência } \\
\text { técnica (\%) }\end{array}$} & \multicolumn{2}{c}{$\begin{array}{c}\text { Número de } \\
\text { propriedades (\%) }\end{array}$} & \multicolumn{2}{c}{ VBP (\%) } \\
\hline Norte & 2006 & 2017 & 2006 & 2017 & 2006 & 2017 \\
Nordeste & $15 \%$ & $10 \%$ & $9 \%$ & $11 \%$ & $6 \%$ & - \\
Sudeste & $8 \%$ & $8 \%$ & $47 \%$ & $46 \%$ & $13 \%$ & - \\
Sul & $31 \%$ & $29 \%$ & $18 \%$ & $19 \%$ & $24 \%$ & - \\
Centro-Oeste & $39 \%$ & $49 \%$ & $19 \%$ & $17 \%$ & $35 \%$ & - \\
\hline Brasil & $30 \%$ & $24 \%$ & $6 \%$ & $7 \%$ & $22 \%$ & - \\
\hline
\end{tabular}

Obs.: VBP - Valor Bruto da Produção.

Fonte: Dados dos Censos Agropecuários de 2006 e 2017, obtidos no IBGE (2018).

Outro aspecto de destaque é a disparidade regional no acesso a essa política entre as diferentes regiões brasileiras. A região Sul, que abrange cerca de $49 \%$ dos estabelecimentos totais, representa apenas $19 \%$ e $17 \%$ daqueles que receberam alguma assistência em 2006 e 2017, respectivamente, enquanto na região Nordeste, que possui $47 \%$ dos estabelecimentos, apenas $8 \%$ receberam algum tipo de assistência técnica. Além disso, observa-se que as regiões que mais receberam serviço de assistência são aquelas com maior participação na formação do VBP nacional. Nesse sentido, uma análise preliminar indica que existem dificuldades de focalização e seletividade da política para atender aos grupos de agricultores que realmente necessitam.

Freitas (2018) identificou o efeito da extensão rural nos níveis de rendimentos e na desigualdade de renda no meio rural brasileiro, com base nos dados da PNAD (Pesquisa Nacional por Amostragem Domiciliar), referente ao ano de 2014. Os resultados permitiram identificar que a extensão rural apresentou um efeito positivo, contribuindo para a obtenção de maiores rendimentos, em todos os quantis de distribuição de renda. Entretanto, o maior efeito identificado, para os quantis mais elevados de renda, evidencia que a política contribuiu para um aumento da desigualdade no meio rural. Observou-se que os grandes estabelecimentos se beneficiam mais da ATER que as propriedades pequenas. Além disso, os serviços privados de extensão apresentaram maior efeito sobre a renda dos produtores considerados. 
O trabalho procurou identificar, também, os condicionantes dos impactos da extensão rural. O maior nível de escolaridade e o fato de o produtor receber financiamento foram os principais fatores que explicaram os maiores rendimentos obtidos pelos produtores atendidos pela extensão rural.

Em relação aos efeitos de sinergia das políticas, identificou-se que maiores níveis de capital humano, conjuntamente com o maior acesso à política de crédito rural e ao próprio serviço extensionista, por parte dos grandes e mais rentáveis domicílios rurais, contribuíram para o agravamento do quadro de desigualdade de renda no meio rural brasileiro. Com isso, podese concluir que somente fornecer extensão rural aos produtores de baixa renda não é garantia de melhoria nos níveis de bem-estar social.

Nesse cenário, apenas o acesso à extensão rural por parte dos produtores mais pobres não será suficiente para elevar os níveis de bem-estar social, visto que o baixo desempenho da política para eles pode estar atrelado às fortes restrições orçamentárias e à carência de outras políticas complementares. É necessária a ação conjunta de outros instrumentos governamentais de forma a promover o desenvolvimento do capital humano e o aumento da oferta de crédito para esse público.

Apesar da complexidade das novas questões que se apresentam para agricultura brasileira, os dilemas na formulação das políticas públicas parecem continuar os mesmos.

\section{REFERÊNCIAS}

BANCO MUNDIAL. Revisão Rápida e Integrada da Gestão de Riscos Agropecuários no Brasil: caminhos para uma visão integrada. Brasília, 2015. $76 \mathrm{p}$.

BRASIL. Lei $\mathrm{n}^{\circ} 4.504$, de 30 de novembro de 1964. Dispõe sobre o Estatuto da Terra, e dá outras providências. Diário Oficial da República Federativa do Brasil. Brasília, 30 nov. 1964. Disponível em: <http://www.planalto.gov.br/ccivil_03/leis/L4504.htm> Acesso em: 14 set. 2018.

BUAINAIN, Antônio Márcio et al. O tripé da política agrícola brasileira: Crédito rural, seguro e Pronaf. In: BUAINAIN Antônio Márcio; ALVES, Eliseu; SILVEIRA, José Maria da; NAVARRO, Zander (Edit.). O mundo rural no Brasil do século 21. Brasília: EMBRAPA, 2014. p. 829-864.

BUAINAIN, Antônio Márcio et al. Sete teses sobre o mundo rural brasileiro. Revista de Política Agrícola, Brasília, ano 22, n. 2, p. 105-121, abr./jun. 2013.

CARVALHO, J. L. Choques externos e a resposta interna: "Semeando vento e colhendo tempestade" na agricultura brasileira. Revista Brasileira de Economia, Rio de Janeiro, v.43, abr./jun., p.139-175, 1989. 
CHADDAD, F.; JANK, M. S.; NAKAHODO, S. Repensando as políticas agrícola e agrária do Brasil. Digesto Econômico, São Paulo, v. 62, p. 6-45, 2006.

FREITAS, Carlos Otávio de. Three essays on the effect of rural extension in the Brazilian agricultural sector. 2017. 122p. Tese (Doutorado em Economia Aplicada) - Programa de Pós-Graduação em Economia Aplicada, Universidade Federal de Viçosa, Viçosa, MG.

INSTITUTO BRASILEIRO DE GEOGRAFIA E ESTATÍSTICA - IBGE. Censo Agropecuário 2006. Disponível em: <www.ibge.gov.br>. Acesso em: 14 set. 2018.

INSTITUTO BRASILEIRO DE GEOGRAFIA E ESTATÍSTICA - IBGE. Censo Agropecuário 2017. Disponível em: <www.ibge.gov.br>. Acesso em: 14 set. 2018.

JOHNSON, D. Gale. Forward prices for agriculture. Chicago: University of Chicago, 1947. 259 p.

JOHNSTON, Bruce F.; MELLOR, John W. The role of agriculture in economic development. The American Economic Review, Wisconsin, v. 51, n. 4, p. 566-593, set. 1961.

LOPES, M. de R. A intervenção do governo nos mercados agrícolas no Brasil: o sistema de regras de intervenção nos mecanismos de preços. Brasília: Companhia de Financiamento da Produção, 1986. 108 p. (Analise e Pesquisa, 33).

MINISTÉRIO DO DESENVOLVIMENTO AGRÁRIO. Políticas públicas para agricultura familiar. Brasília, 2013. 104p.

MUELLER, C. C. A política agrícola no Brasil: Uma visão de longo prazo. Revista de Política Agrícola, Brasília, ano 19, p. 9-23, 2010. Edição Especial de Aniversário do Mapa - 150 anos.

PEIXOTO, M. A extensão privada e a privatização da extensão: uma análise da indústria de defensivos agrícolas. 2009. 331 p. Tese (Doutorado em Ciências Sociais) - Programa de Pós-Graduação de Ciências Sociais em Desenvolvimento, Agricultura e Sociedade, Universidade Federal do Rio de Janeiro, Rio de Janeiro.

SANTANA, Carlos A. M. et al. Política agrícola: avanços e retrocessos ao longo de uma trajetória positiva. In: BUAINAIN Antônio Márcio; ALVES, Eliseu; SILVEIRA, José Maria da; NAVARRO, Zander (Edit.). O mundo rural no Brasil do século 21. Brasília: EMBRAPA, 2014, p. 795-826.

SMITH, G. W. Brazilian agricultural policy: 1950-67. In: ELLIS, H. S. (Coord.). The economy of Brazil. Berkeley: University of California Press, 1968. p. 213-265. 